\title{
Exercise-Based and Associated Factors Breastfeeding on HIV-Infected Mothers for Children Age 1-24 Months in Central Zone, Tigray, North Ethiopia, 2019.
}

Hamelmal Mekonen Embaye

Adigrat University

Teferi Gebru Gebremeskel ( $\square$ teferigebru12@gmail.com )

Aksum University https://orcid.org/0000-0002-8276-5685

\section{Research}

Keywords: practice, attitude, Exclusive breastfeeding, HIV positive Mothers

Posted Date: March 10th, 2020

DOI: https://doi.org/10.21203/rs.3.rs-16522/v1

License: (c) (1) This work is licensed under a Creative Commons Attribution 4.0 International License.

Read Full License 


\section{Abstract}

Background: Breastfeeding exposed to HIV is a major factor in the spread of HIV, but breastfeeding alone poses a significant risk to the baby's health because breastfeeding can reduce the impact of many infections and support some chronic diseases. Therefore, this study was aimed to assess exercise-based and associated factors breastfeeding on HIV-infected mothers for children age 1-24 months in the central zone, Tigray, north Ethiopia.

Methods: A Facility-based Cross-Sectional study was conducted from March to April 2019. A systematic random sampling method was used to select study participants. Information was collected using a structured, pre-tested questionnaire. The data is coded, cleaned, copied and entered EPI-info 7 and finally export to SPSS version 22.00 for analysis. Association between independent and dependent variables was first analyzed using binary logistic regression analyses. An alternative bivariate logistic regression analyzes of less than 0.2 were entered in multivariable logistic regression analysis. The statistical association between variance dependent and independent variables was measured using an $O R, A O R$, $95 \% \mathrm{Cl}$, and a p-value less than 0.05 .

Result: 239 HIV-positive mothers participated in this study. Approximately 204(85.4) are favorable attitude in the practice of exclusive breastfeeding. The majority of mothers 206 (86.7\%) experienced good breastfeeding. Mothers with Information while exclusive breastfeeding (AOR, 2.57, 95\%Cl: 1.03- 6.4) and age at first birth (AOR: .247, 95\%: (.106- .578) had a significant collaboration on exclusive breastfeeding practice among HIV-infected mothers. Several ANC visits have had a significant collaboration on exclusive breastfeeding practice among HIV-infected mothers (AOR; 3.726 95\% Cl; 1 .055-13.154).

Conclusion: The study found that HIV positive mothers attending health care facilities had a favorable attitude but practiced on EBF is still low. Therefore, train health professionals especially health extension workers to raise awareness education, enhance information, regarding EBF and strength counseling in ANC service is better to improve the HIV positive mother level of attitude and practice to EBF.

\section{Background}

Breastfeeding exposed to HIV is a major factor in the spread of HIV, but breastfeeding alone poses a significant risk to the baby's health because breastfeeding can reduce the impact of many infections and support some chronic diseases and breastfeeding. Diet exercise is generally the best baby diet choice for all women(1).

Globally, over 10 million children under five die each year and $40 \%$ of diseases under the age of two are associated with inappropriate breastfeeding, $34 \%$ of which occur in South Asia and $41 \%$ in sub-Saharan Africa (2).In addition to breastfeeding, 300,000 HIV infections occur annually, while at the same time the United Nation Children Emergency Fund (UNICEF) is not responsible for the deaths of 1.5 million children in one year, and the biggest burden of this infection, Sub-Saharan Africa (3). 
In the first year of the world, two-thirds of all deaths in the world often follow appropriate nutritional practices, especially due to unspecified breastfeeding activities(4). In the developing world, including Ethiopia, 3000-4000 infants per day die from diarrhea and respiratory infections associated with high levels of disease(5).

In Ethiopia, 321,000 children under five years of age die from malnutrition, with $57 \%$ of death each being primarily prevented by breastfeedings, such as diarrhea and pneumonia. (6).

About $40 \%$ of the world population, $47 \%$ in Africa, and $58 \%$ in Ethiopia, according to Ethiopian demographic and health survey (EDHS) 2016, have increased the number of children under 0-6 months. $(7,8)$.

Study show's in India 30.6\% (9) southern Ethiopia, Mekelle and central zone Tigray show that attitude towards exclusive breastfeeding about $56.7 \%, 81.6 \%$ and $82.6 \%$ of HIV mothers had favorable attitudes towards EBF (10-12).

Study in Botswana 20\%(13), southwestern Nigeria 61\%(14), Burkina Faso52.5\% (15), Kenya40.6\%(16), Southern Ethiopia 82.8\%(17), in Bahir Dar75.2\% (18), Gondar 89.5\%(19) and west oromia72\%(20) and central zone, Tigray about $90 \%$ (21) shows that mothers who are HIV positive breastfed were practiced exclusively breastfeeding for the first 6 months respectively.

Recent study identified that predictor for attitude and practice exclusives breastfeeding among mothers living with HIV/AIDS were mother's occupation, residence, knowledge on EBF practice, ANC service, counseling on EBF practice during ANC visit, insufficient breast milk, husband imposition, mother's illness and both mother's and infant's illness, income, maternal choice of maternal-infant feeding practice and cultural (10-21) Therefore, this study was aimed at assessing attitude, practice and determinant factors affecting exclusives breastfeeding among mothers living with HIV/AIDS have children age 0-24 months in central zone Tigray.

\section{Methods}

A facility-based cross-sectional study was conducted from March to April 2019, at Central zone Tigray regional state of Ethiopia. The central zone is $1024 \mathrm{~km}$ from Ethio -capital, Addis Ababa, $240 \mathrm{~km}$ from the capital city of Tigray. The central zone was divided into 12 weredas, of which 631,972 were female and 613,251 were males. The total number of people living with HIV was 4841 , the reproductive-age women who are HIV positive were 2028 and HIV positive mothers who have an infant less than or equal to 24 months were 485 . There were 72 health centers ( 20 of them have ART service), 6 primary hospitals, 3general hospitals, and 1 referral hospital.

All HIV positive mothers with children younger than or equal 24 months were recruited as a study group within the designated public health facility's central zone. All HIV-positive mothers who gave birth within 
24months before the study were included, excluded, had no mental illness or had several mental illnesses during data collection.

Considering $82 \%$ of exclusive breastfeeding rate for children under six months of age (21), $95 \%$ confidence level, $5 \%$ tolerable margin of error, $5 \%$ unresponsive, a total sample of 239 were considered. to test the consistency of sample size, Epi-info was considered to be the only breastfeeding practice considering the relevant aspect of the observation. It was larger than the EPi-info by comparing a sample size based on a population. Therefore, the largest sample size of 239 was determined.

Considering all public health institutions in the Tigray region of the Central Zone, the sample size visited all public health institution s based on the number of children under or equal the age of 24 months who were HIV positive mother, round up. Participants in the study were selected for each of the 2 HIV-infected mothers of a randomized random sampling method, equal to 24 months.

Attitude and practice Exclusive Brest feeding was considered as the dependent variable. Sociodemographic and Reproductive characteristics, knowledge exclusive breastfeeding, Institutional and source of information related factors were considered as the independent variable.

The attitude of exclusive breastfeeding - Good (Positive) attitude (scores $>60 \%$ ) on the overall attitude question (17).

Good practice of exclusive breastfeeding -mothers answer (score $>60 \%$ ) on the overall practice question (17).

Keble: A small administrative unite consisting of 20.000 population.

The information was collected using the questionnaire and a structured questionnaire from a variety of similar research $(15,17,19)$ if there was a change in the context of the study. Face-to-face breastfeeding alone was tested during a panel discussion with 12 women and one of the women in questionnaire accuracy and translation quality questionnaire. A few questions for language transparency and information were reviewed and the questionnaire was completed for the study. The applicant includes a source of social and demographic, reproductive history, institutional and informational sources.

Five health care professionals and two supervisors were recruited from the health center and trained for one day. Supervisors follow a daily data collection process and communicate with investigators every day to check the consistency of the data.

The data is coded, cleaned, copied and entered EPI-info 7 and finally export to SPSS version 22.00 for analysis. A simple descriptive summary was made. Table, diagrams, descriptions, charts, and graphs were used to produce the result of the analyzed data. After that, you can combine the filters into the corresponding catalogs using a chi-square test variable with small cell size. An alternative bivariate logistic regression analyzes of less than 0.2 were entered in multivariable logistic regression analysis. Appropriate fitness testing done well more than 0.2 predicted variants and a multiple-choice test between 
Hosmer and Lemeshow test P-value to assess model performance. The statistical association between various independent variables was measured using an $\mathrm{OR}, \mathrm{AOR}, 95 \% \mathrm{Cl}$, and a p-value less than 0.05 .

\section{Results}

\section{Socio-demographic characteristics of mothers}

A total of 239 HIV positive mothers participated in a response rate of $100 \%$. Out of the total participated mothers, $175(73.5 \%)$ were with an age range of $25-35$ years. The majority of the participants $177(73.8 \%)$ were married (Table 1).

\section{Health institutions related factors and source of information}

Three fourth of the respondents $(75.8 \%)$ reported that they had to get information about EBF from health professionals. Among them, $97.9 \%$ of these respondents had availability of health care facilities in your area. (Table 2).

\section{Reproductive characteristics of mothers}

The majority of the respondent's $74.4 \%$ mother's age at marriage was $18-24$ years. Among them, $54.2 \%$ of mothers their child age from 6 months up to 12 months. From total respondents, about $95.8 \%$ attended ANC follow and about $76.6 \%$ were from 3-4 ANC follow up (Table 3).

\section{Knowledge of EBF among HIV positive mothers}

In our study majority respondents, $93.7 \%$ heard about exclusive breastfeeding, among this $92.4 \% \mathrm{knew}$ the importance of exclusive breastfeeding for child health. About knowledge on EBF HIV positive mother, $88.2 \%$ of the respondents know HIV seropositive mother can breastfeed, $90.8 \%$ know foods or fluids recommended to under 6-month child is only breast milk and about $35.6 \%$ know times baby breastfeeding per day were from 8-10 times (Table 4).

\section{The attitude of EBF among HIV positive mothers}

In our study more than three fourth respondents, $78.6 \%$ believed that breast milk was free from any contamination; among this $86.6 \%$ believe that EBF is better than artificial feeding. $80.9 \%$ of HIV seropositive mothers strongly recommended breastfeeding, and $10 \%$ of participants believe that is important to eat food six months ago. Of the total respondent, $83.6 \%$ had a positive attitude about EBF for up to six months. (Table 5). 


\section{EBF practice among HIV-positive mothers}

Most, $214(89.5 \%)$ of mothers feed their last baby on the mother's breast. The majority of the participants reported that $194(90.6 \%)$ of mothers started breastfeeding immediately within one hour after birth. $102(42.5 \%)$ of all breastfeeding was 8-10 times a day. Most mothers reported $74.6 \%$ of explicit breastfeeding exercises for your baby up to six months, $20.8 \%$ of respondents had 6 to 12 months and $1.3 \%$ of mothers over 12 months. It was $86.2 \%$ of all positive experiences. (Table 6 ).

\section{Factors associated with the attitude of EBF among HIV positive mothers}

In bivariate analysis, maternal educational status, mothers who had Information on the term of EBF, types of health care facility available, age at first birth and numbers of postnatal care visits were significant association with exclusive breastfeeding attitude among HIV positive mothers. In multivariate analysis, mothers who had information on the term of EBF and age at first birth had significantly associated with an attitude of HIV positive mothers on EBF (AOR: $p<0.05)$. HIV positive mothers who had Information on the term of EBF 2.57 more likely favorable attitude than mothers who had no information on the term of EBF (AOR,2.57,95\% Cl: 1.03- 6.4). HIV positive mothers whose age at first birth 24 and above were 0.247 times less likely had favorable attitude than HIV positive mothers whose age at first birth were 18-24 years (AOR.247, 95\%: (.106- .578).(Table 7)

\section{Factors associated with the practice of EBF among HIV positive mothers}

In bivariate analysis, maternal educational level, number of gravidities, number of ANC visits, types of health care facility available and Income had a significant association with exclusive breastfeeding practice among HIV positive mothers and those candidate variables for multivariate logistic regression. In a multivariate analytical number of ANC visit only had a significant association with exclusive breastfeeding practice among HIV positive mothers, mothers were 3-4 numbers of ANC visit had 3 times more likely practice on exclusive breastfeeding than mothers were ANC visits' less than or equal 2 ( AOR; 2.981,95\%Cl;1.113-7.983). (Table 8).

\section{Discussions}

This study was a case study of cognitive functioning and corresponding breastfeeding status among HIV-infected mothers who participated in PMTCT and ART services in selected health education of the central zone, Tigray, Ethiopia. In this study, two hundred five (85.4) of the HIV infected mother reported the mother had a positive attitude towards the EBF experience. This source study conduct in Botswana $56.3 \%$ (13), is higher than a study. This may be the single most effective and effective treatment for children 
under six months of age. This finding is higher than another study conducted in southern Ethiopia (56.7\% ) and central zone Tigray $82.6 \%$ respectively. This difference may be due to health services and health education $(17,21)$.

In this study, the mother, who had information about EBF status and age at first birth, had played a significant role in the attitudes toward EBF on the HIV positive mothers. HIV positive mothers who have had information on the term of EBF three times more likely favorable attitude than mothers who had no information on the term of EBF. This may be due to poor information or poor advice on dietary options for children under six months. HIV positive mothers whose age at first birth 24 and above was $24 \%$ times less likely had favorable attitude than HIV positive mothers whose age at first birth were 18-24 years. This may be due to poor advice on the risk of HIV transmission to your baby and breastfeeding alone.

In this study, two hundred six (86.2) of HIV positive mothers had good practice towards EBF practice. This finding is higher than the study conducted in India 30.6\% (9), Tanzania ilala municipality dares salaam46\% (22), Botswana 20\% (13), western Nigeria 61\% (14) and in Burkina Faso, 52.5\%(15) of HIV positive mothers were practice exclusively breastfed to their children. This discrepancy might be due to socio-demographic characteristics and the availability of health services.

In this study, about $85 \%$ of HIV positive mothers initiated breastfeeding within the recommended first hour of birth. this result was higher than the study conducted in Oromia regional $69.3 \%$ and Southern Ethiopia shows that $51.5 \%$ initiated breastfeeding within the recommended first hour of birth $(20,17)$.

In this study, HIV positive mothers practiced complementary feeding at 6 months of life were $53.3 \%$.this finding is lower than the study done in Southern Ethiopia that $77.2 \%$ mothers practiced complementary feeding at 6 months of life (17).

This study also found out that $86.7 \%$ of HIV positive mothers were practiced exclusive breastfeeding This finding was higher than from a study done in Bahir Dar $75.2 \%$ and

west Oromia $72 \%$ practiced exclusive breastfeeding $(17,20)$. However, this study finding is lower the study done Gondar town $89.5 \%$ and Mekelle town, 90 \% of HIV positive mothers had practiced exclusive breastfeeding $(11,18)$. In this finding number of ANC visits had a significant association with exclusive breastfeeding practice among HIV positive mothers, mothers were 3-4 numbers of ANC visits had $37 \%$ more likely practice on exclusive breastfeeding than mothers were ANC visits' less than or equal 2 . This may be to increasing contact with the health care provider and to provide information on breastfeeding practices, particularly in EBF practice.

\section{Conclusion}

The study found that HIV positive mothers attending health care facilities in the central zone, the Tigray region had a favorable attitude but practiced on EBF is still low. Factor such as Information on the term of EBF and age at first birth was associated with attitude toward EBF and the Number of ANC visits was 
associated with practice on EBF. Therefore, train health professionals especially health extension workers to raise awareness education, enhance information, regarding EBF and strength counseling in ANC service is better to improve the HIV positive mother level of attitude and practice to EBF.

\section{Declarations}

\section{Ethics approval and consent to participant}

Ethical clearance was obtained from the Institutional Review Committee (IRC), College of Medicine and Health Sciences, University of Aksum. Permission letter was received from those administrative bodies of the Central Tigray Health Department and each health facility's verbal and written consent was obtained from all participants after they informed on the purpose of the study.

\section{Consent for publication}

Not applicable

\section{Availability of data and materials}

All relevant data are within the manuscript and its Supporting Information files.

\section{Computing interest}

The authors declare that they have no competing interests.

\section{Funding}

"The authors received no specific funding for this work".

\section{Authors' contributions}

HM and TG designed the study, performed the statistical analysis, drafted the paper, data analysis and read and approved the final paper.

\section{Acknowledgments}

We are highly indebted to all participants of the study, supervisors of data collection and data collectors for their worthy efforts and participation in this study.

\section{Authors' details}

Hamelmal Mekonen (MPH-RH): Department of Reproductive Health, College of Health Sciences, Adigrat University, Adigrat, Ethiopia. Email:Hamelmalmekonen123@gmail.com 
Teferi Gebru Gebremeskel (MPH-RH): Department of Reproductive Health, College of Health Sciences, Aksum University, Aksum, Ethiopia. Email: teferigebru12@gmail.com

\section{References}

1. Organization WH. Guidelines on HIV and infant feeding 2010: principles and recommendations for infant feeding in the context of HIV and a summary of the evidence: Geneva: World Health Organization; 2010.

2. Begum K, Dewey KG. Impact of early initiation of exclusive breastfeeding on newborn deaths. 2010 .

3. Fletcher FE, Ndebele P, Kelley MC. Infant feeding and HIV in Sub-Saharan Africa: what lies beneath the dilemma? Theoretical medicine and bioethics. 2008;29(5):307.

4. Organization WH. WHO. Exclusive breastfeeding for six months best for babies everywhere. Geneva: World Health Organization; 2011 [cited 2016 Jul 19].

5. Abera K. Infant and young child feeding practices among mothers living in Harar, Ethiopia. Harar Bulletin of Health Sciences. 2012;4:66-78.

6. Atindanbila S, Mwini-Nyaledzigbor P, Abasimi E, Benneh CO, Avane MA. Attitudes and practices associated with exclusive breastfeeding (EBF) of nursing mothers in Bolgatanga Municipality. 2014.

7. Organization WH. facts on breastfeeding. WHO. Updated August 2017.

8. EDHS ED. Health Survey. Key indicators report. 2016.

9. Bashir A, Mansoor S, Naikoo MY. Knowledge, attitude, and practices of postnatal mothers regarding breastfeeding: A cross-sectional study. International Journal of Medical Science and Public Health. 2018;7(9):725-31.

10. Modjo KE, Amanta NW. Attitude and Practice Towards Exclusive Breast Feeding and Its Associated Factors Among HIV Positive Mothers in Southern Ethiopia. American Journal of Health Research. 2015;3(2):105.

11. Girma Y, Biruh G. Infant feeding practice and associated factors among HIV positive mothers enrolled in governmental health facilities in Mekelle town, Tigray region, North Ethiopia. Journal of HIV/AIDS and infectious disease. 2014;2(401).

12. Bashir A, Mansoor S, Naikoo MY. Knowledge, attitude, and practices of postnatal mothers regarding breastfeeding: A cross-sectional study. International Journal of Medical Science and Public Health. 2018;7(9):725-31.

13. Ndubuka J, Ndubuka N, Li Y, Marshall CM, Ehiri J. Knowledge, attitudes and practices regarding infant feeding among HIV-infected pregnant women in Gaborone, Botswana: a cross-sectional survey. BMJ Open. 2013;3(11):e003749.

14. Aishat U, David D, Olufunmilayo F. Exclusive breastfeeding and HIV/AIDS: a crossectional survey of mothers attending prevention of mother-to-child transmission of HIV clinics in southwestern Nigeria. Pan African medical journal. 2015;22(1). 
15. Coulibaly M, Thio E, Yonaba C, Ouédraogo S, Meda N, Dahourou DL, et al. Prevention and care of pediatric HIV infection in Ouagadougou, Burkina Faso: knowledge, attitudes, and practices of the caregivers. BMC pediatrics. 2016;16(1):33.

16. Jepkogei KW. Determinants of adherence to exclusive breastfeeding among HIV positive mothers attending child welfare clinic at Pumwani maternity hospital, Nairobi County, Kenya. Nairobi: Kenyatta University. 2013.

17. Modjo KE, Amanta NW. Attitude and Practice Towards Exclusive Breast Feeding and Its Associated Factors Among HIV Positive Mothers in Southern Ethiopia. American Journal of Health Research. 2015;3(2):105.

18. Sendo E, Mequanint F, Sebsibie G. Infant Feeding Practice and Associated Factors among HIV Positive Mothers Attending ART Clinic in Governmental Health Institutions of Bahir Dar Town, Amhara Regional State, Ethiopia, 2017. J AIDS Clin Res. 2018;9(755):2.

19. Ekubagewargies DT, Mekonnen HS, Siyoum TM. Assessment of Knowledge, Attitude, and Practice of HIV Positive Mothers on Antiretroviral Treatment towards Infant Feeding in Gondar Town Health Institutions, North West Ethiopia, 2017. International Journal of Pediatrics.2019.

20. Bekere A, Garoma W, Beyene F. Exclusive Breastfeeding Knowledge of HIV Positive mothers and Associated Factors in Selected Health Institution of West Oromia, Ethiopia. Universal Journal of Food and Nutrition Science. 2014;2(3):37-44.

21. Hiwot, A.G., Silassie, K.H., Mirutse, G.M. and Alem Desta, H.A., 2014. Infant feeding practice of HIV positive mothers and its determinants in public health institutions in the central zone, Tigray Region, Northern Ethiopia. International Journal of Pharma Sciences and Research (IJPSR).

22. Saka FJ. Factors influencing exclusive breastfeeding among HIV positive mothers at llala Municipality Dar es Salaam: the Muhimbili University of Health and Allied Sciences; 2012.

\section{Tables}

Table 1: Socio-demographic characteristics of HIV positive mothers on EBF in a public health facility central zone, Tigray, Ethiopia, 2019. 


\begin{tabular}{|c|c|c|c|}
\hline Variables & Response & Frequency & percent \\
\hline \multirow[t]{4}{*}{ Maternal age } & From 15-24 year & 6 & 2.5 \\
\hline & From 25-35 year & 175 & 73.5 \\
\hline & Above 35 year & 58 & 24.2 \\
\hline & Total & 239 & 100 \\
\hline \multirow[t]{3}{*}{ Ethnicity } & Tigray & 230 & 96.2 \\
\hline & Amhara & 8 & 3.3 \\
\hline & Oromo & 1 & 0.4 \\
\hline \multirow[t]{3}{*}{ Religion } & Orthodox & 217 & 90.8 \\
\hline & Protestant & 2 & 0.8 \\
\hline & Muslim & 20 & 8.4 \\
\hline \multirow{2}{*}{ Residence } & urban & 205 & 85.5 \\
\hline & rural & 34 & 14.2 \\
\hline \multirow{3}{*}{ Education states of mothers } & Illiterate & 95 & 39.7 \\
\hline & Literate & 144 & 60.3 \\
\hline & Total & 239 & 100 \\
\hline \multirow[t]{3}{*}{ mothers occupation } & Nonemployee & 119 & 49.8 \\
\hline & Employed & 120 & 50.2 \\
\hline & Total & 239 & 100 \\
\hline \multirow[t]{4}{*}{ marital status } & Married & 177 & 73.8 \\
\hline & never married & 21 & 8.8 \\
\hline & Divorced & 34 & 14.2 \\
\hline & Widowed & 8 & 3.3 \\
\hline \multirow[t]{3}{*}{ husband's educational level } & Illiterate & 72 & 30.1 \\
\hline & Literate & 116 & 48.5 \\
\hline & Total & 188 & 78.7 \\
\hline \multirow[t]{3}{*}{ husband's occupation } & Nonemployee & 80 & 33.5 \\
\hline & Employed & 108 & 45.2 \\
\hline & Total & 188 & 78.7 \\
\hline \multirow{3}{*}{$\begin{array}{l}\text { average monthly income of your } \\
\text { family }\end{array}$} & Lessthan1000birr & 39 & 16.3 \\
\hline & From 1000-1500 & 54 & 22.6 \\
\hline & Above1500 & & 61.1 \\
\hline
\end{tabular}

Table2: Health Institutions related factors and source of information on EBF among HIV positive mothers in public health facility central zone, Tigray, Ethiopia 2019. 


\begin{tabular}{|c|c|c|c|}
\hline Variables & Response & Frequency & percent \\
\hline heard of any those EBF & Yes & 194 & 81.2 \\
\hline & No & 45 & 18.2 \\
\hline Sources of information about EBF? & Health & 182 & 75.8 \\
\hline & professionals & 28 & 11.7 \\
\hline & Media & 2 & 0.8 \\
\hline & Reading & 3 & 1.3 \\
\hline & books & 1 & 0.4 \\
\hline & $\begin{array}{l}\text { Family/ Friend } \\
\text { Magazines }\end{array}$ & & \\
\hline type of media use & Television & 156 & 65 \\
\hline & Radio & 50 & 20.8 \\
\hline & Newspaper & 2 & 0.8 \\
\hline & Magazine & 10 & 4.2 \\
\hline Availability of health care facility in your area & Yes & 234 & 97.9 \\
\hline & No & 5 & 2.1 \\
\hline Type of health facilities in your area & Health post & 19 & 7.9 \\
\hline & health center & 105 & 43.8 \\
\hline & $\begin{array}{l}\text { hospital } \\
\text { private clinic }\end{array}$ & 116 & 48.3 \\
\hline The distance of health facilities from your home on & Less than 30 & 129 & 53.8 \\
\hline foot. & minute & 93 & 38.8 \\
\hline & 30 minute to & 14 & 5.8 \\
\hline & one hour & & \\
\hline & One hour to & & \\
\hline & two hour & & \\
\hline & More than two & & \\
\hline Cost of care influence your services & yes & 31 & 13 \\
\hline & no & 208 & 87 \\
\hline Healthcare staffs have a good approach for you & Yes & 226 & 94.6 \\
\hline where you have utilized healthcare service & No & 13 & 5.4 \\
\hline
\end{tabular}

Table 3 Reproductive characteristics of HIV positive mothers on EBF in public health facility central zone, Tigray, Ethiopia 2019. 


\begin{tabular}{|c|c|c|c|}
\hline Variables & Response & Frequency & percent \\
\hline \multirow[t]{2}{*}{ age at marriage } & From18-24 years & 221 & 92.5 \\
\hline & Greater than 24 year & 18 & 7.5 \\
\hline \multirow[t]{2}{*}{ age at first birth } & From18-24 years & 191 & 79.9 \\
\hline & Greater than 24 year & 48 & 20.1 \\
\hline \multirow[t]{3}{*}{ Age of the child in the month } & Less than 6 month & 38 & 15.8 \\
\hline & 6-12 month & 130 & 54.2 \\
\hline & Greater than 12 month & 72 & 30 \\
\hline \multirow[t]{2}{*}{ Sex of the child } & male & 127 & 52.9 \\
\hline & female & 113 & 47.1 \\
\hline \multirow[t]{3}{*}{ Gravidity } & Primi gravida & 141 & 59 \\
\hline & multigravida & 77 & 32.2 \\
\hline & grand multigravida & 21 & 8.8 \\
\hline \multirow[t]{3}{*}{ Parity } & Primi Para & 188 & 78.7 \\
\hline & multi Para & 42 & 17.6 \\
\hline & grand multi Para & 9 & 3.8 \\
\hline \multirow{2}{*}{ ANC service pregnancy } & Yes & 229 & 95.8 \\
\hline & No & 10 & 4.2 \\
\hline \multirow[t]{3}{*}{ Numbers of ANC follow up } & $1-2$ & 32 & 13.4 \\
\hline & $3-4$ & 184 & 76.6 \\
\hline & Above 4 & 23 & 10 \\
\hline \multirow[t]{2}{*}{ given $\mathrm{HE}$ on $\mathrm{BF}$ during the $\mathrm{ANC}$} & Yes & 214 & 89.2 \\
\hline & No & 25 & 10.2 \\
\hline \multirow{3}{*}{ Place of birth to this child } & $\mathrm{HC}$ & 58 & 24.2 \\
\hline & Hospital & 179 & 74.6 \\
\hline & Home & 3 & 1.3 \\
\hline \multirow{2}{*}{ PNC service } & Yes & 192 & 80.4 \\
\hline & No & 47 & 19.6 \\
\hline \multirow[t]{3}{*}{ Numbers of PNC } & One visit & 204 & 85.4 \\
\hline & $2-3$ visit & 28 & 11.4 \\
\hline & $>3$ visit & 7 & 2.9 \\
\hline \multirow[t]{3}{*}{ HE on BF during PNC } & $\mathrm{HC}$ & 53 & 22.1 \\
\hline & Hospital & 142 & 59.2 \\
\hline & Home & 1 & 0.4 \\
\hline
\end{tabular}

Table 4: Knowledge of HIV positive mothers on EBF in public health facility central zone, Tigray, Ethiopia 2019 
Variables

Ever heard the term EBF

infant feeding per day

The right time to give breast milk to the child after birth

breastfeeding important for child health

Importance of breastfeeding
Response

Yes

no

As needed

From 8-10

Above10

Less than 8

After giving some

better

Within one hour

After one hour

After 24 hours

Yes

No

Prevent diarrhea

Minimize cost

Sterile

Growth and

development

Increases bonding
Duration of newborns be fed breast milk only

Age of complementary feeding be initiated

Duration of breastfeeding be continued

Foods or fluids recommended to under 6-month child

\section{Less than 6 month}

6-12 month

Above 12 month

At 6 month

Less than 6 month

6-12 month

Above 12 month

Less than 6 month

6-12 month

Above 12 month

Only breast milk

Breast milk and /o

water or sugar

formula

Others

pre-lacteal feeding needed for an infant before

starting breast milk

Is $\mathrm{BM}$ alone is enough for an infant $<6$ month of life

EBF for the first 6 months used to prevent

diarrhea and Respiratory disease for the infant

HIV seropositive mother breastfeed

HIV positive mother knowledge of EBF
Yes

No

I do not know

Yes

No

I do not know

Yes

No

I do not know

Yes

No

Good Knowledge 211

Poor Knowledge

12

33
Frequency percent

$224 \quad 93.7$

15

103

6.3

42.9

$85 \quad 35.6$

$11 \quad 4.8$

$\begin{array}{ll}40 & 16.9\end{array}$

8

$205 \quad 85.6$

$23 \quad 9.8$

$3 \quad 1.3$

$221 \quad 92.4$

$18 \quad 7.6$

$96 \quad 40$

$18 \quad 7.5$

$14 \quad 5.8$

$89 \quad 37.1$

$\begin{array}{ll}4 & 1.7\end{array}$

$169 \quad 70.4$

$49 \quad 20.4$

$18 \quad 7.5$

$137 \quad 57.3$

34

95

14.2

39.6

2.9

6.3

18.5

75.2

179

90.5

4.7

4.3

0.5

5.8

78.8

15.4

90.1

4.6

5.3

82.9

$\begin{array}{ll}199 & 82.9 \\ 7 & 2.9\end{array}$

14.2

$211 \quad 88.2$

$\begin{array}{ll}28 & 11.8\end{array}$

88.4

11.6

Table 5: Attitude of HIV positive mothers on EBF in public health facility central zone, Tigray, Ethiopia 2019 
Breast milk is free from any contamination.$$
\text { strong }
$$

Agree

Agree

Disagree

strong

disagree

Not sure

Giving breast milk for a baby immediately within an hour after birth is important

strong

Agree

Agree

Disagree

strong

disagree

EBF is better than artificial feeding

$\begin{array}{ll}\text { strong } & 62 \\ \text { Agree } & 152 \\ \text { Agree } & 12 \\ \text { Disagree } & 3 \\ \text { strong } & 10 \\ \text { disagree } & \\ \text { Not sure } & \end{array}$

Discarding colostrums is important before giving breast milk to a newborn

Not sure

strong

Agree

Agree

Disagree

strong

disagree Not

sure

Giving a child of three months only breast milk may not be sufficient and a child needs water and other fluids to prevent thirst

strong

Agree

Agree

Disagree

strong

disagree Not

sure

Starting complementary foods to a child before six months is important

strong

Agree
Agree

Disagree

strong

disagree Not

sure

Only breastfeeding is enough for the baby for up to six months.

Breast milk contains all the nutrients necessary for the infant for up to 6 months.

\section{s}

strong

Agree

Agree

Disagree

strong

disagree Not

sure

strong

Agree

Agree

Disagree

strong

disagree Not percent

31.3

47.4

17.1

0.4

3.8

32.5

62.9

1.7

2.9

$62 \quad 25.8$

$152 \quad 63.7$

$12 \quad 5$

$3 \quad 1.2$

$10 \quad 4.1$

5
1.2
4.1

$\begin{array}{ll}4 & 1.7\end{array}$

$36 \quad 15$

$139 \quad 58.3$

$\begin{array}{ll}28 & 11.7\end{array}$

$\begin{array}{ll}32 & 13.3\end{array}$

$\begin{array}{ll}2 & 0.8\end{array}$

$13 \quad 5.4$

$182 \quad 75.9$

$\begin{array}{ll}25 & 10.4\end{array}$

$\begin{array}{ll}17 & 7.5\end{array}$

.7
5
8.3
1.7
3.3

0.8
5.4
75.9
10.4
7.5

1.7

8.3

81.7

5

3.3

$\begin{array}{ll}4 & 1.7 \\ 20 & 8.3 \\ 195 & 81.7 \\ 12 & 5 \\ 8 & 3.3\end{array}$

62

25.8

58.8

10.4

0.4

4.6

$\begin{array}{ll}141 & 58.8 \\ 25 & 10.4 \\ 1 & 0.4 \\ 10 & 4.6\end{array}$

52

21.7

$155 \quad 64.6$

$13 \quad 5.4$

$3 \quad 1.3$

16 
sure

\begin{tabular}{|c|c|c|c|}
\hline & & & \\
\hline $\begin{array}{l}\text { Breast milk provides the infant with the immunity to } \\
\text { disease. }\end{array}$ & $\begin{array}{l}\text { strong } \\
\text { Agree } \\
\text { Agree } \\
\text { Disagree } \\
\text { strong } \\
\text { disagree Not } \\
\text { sure }\end{array}$ & $\begin{array}{l}67 \\
151 \\
8 \\
1 \\
12\end{array}$ & $\begin{array}{l}27.6 \\
63 \\
3.3 \\
0.4 \\
5.7\end{array}$ \\
\hline Mixed feeding is always necessary for infants & $\begin{array}{l}\text { strong } \\
\text { Agree } \\
\text { Agree } \\
\text { Disagree } \\
\text { strong } \\
\text { disagree Not } \\
\text { sure }\end{array}$ & $\begin{array}{l}8 \\
26 \\
157 \\
32 \\
16\end{array}$ & $\begin{array}{l}3.3 \\
10.8 \\
65.5 \\
13.3 \\
7.1\end{array}$ \\
\hline $\begin{array}{l}\text { Dealing with breastfeeding is always time- } \\
\text { consuming. }\end{array}$ & $\begin{array}{l}\text { strong } \\
\text { Agree } \\
\text { Agree } \\
\text { Disagree } \\
\text { strong } \\
\text { disagree Not } \\
\text { sure }\end{array}$ & $\begin{array}{l}3 \\
34 \\
181 \\
19 \\
2\end{array}$ & $\begin{array}{l}1.3 \\
14.2 \\
75.8 \\
7.9 \\
0.8\end{array}$ \\
\hline $\begin{array}{l}\text { Breastfeeding affects the health of the mother } \\
\text { negatively. }\end{array}$ & $\begin{array}{l}\text { strong } \\
\text { Agree } \\
\text { Agree } \\
\text { Disagree } \\
\text { strong } \\
\text { disagree Not } \\
\text { sure }\end{array}$ & $\begin{array}{l}5 \\
20 \\
171 \\
31 \\
7\end{array}$ & $\begin{array}{l}2.1 \\
8.3 \\
73.8 \\
12.9 \\
2.9\end{array}$ \\
\hline HIV seropositive mother recommend breastfeeding & $\begin{array}{l}\text { strong } \\
\text { Agree } \\
\text { Agree } \\
\text { Disagree } \\
\text { strong } \\
\text { disagree Not } \\
\text { sure }\end{array}$ & $\begin{array}{l}58 \\
135 \\
32 \\
3 \\
11\end{array}$ & $\begin{array}{l}24.5 \\
56.3 \\
13.3 \\
1.3 \\
4.6\end{array}$ \\
\hline & $\begin{array}{l}\text { Favorable } \\
\text { Attitude } \\
\text { Unfavorable } \\
\text { Attitude }\end{array}$ & $\begin{array}{l}204 \\
35\end{array}$ & $\begin{array}{l}85.4 \\
14.6\end{array}$ \\
\hline
\end{tabular}

Table 6: Practice of HIV positive mothers on EBF in public health facility central zone, Tigray, Ethiopia 2019. 


\begin{tabular}{|c|c|c|c|}
\hline \multirow[t]{2}{*}{ Variables } & \multirow[t]{2}{*}{ Response } & \multicolumn{2}{|l|}{ Frequency } \\
\hline & & & percent \\
\hline \multirow[t]{2}{*}{ Breastfeed your last-child } & Yes & 214 & 89.5 \\
\hline & No & 25 & 10.5 \\
\hline \multirow{3}{*}{$\begin{array}{l}\text { Initiation of breastfeeding for your last child } \\
\text { after delivery }\end{array}$} & Immediately within 1 & 194 & 90.6 \\
\hline & hour & 17 & 8 \\
\hline & $\begin{array}{l}\text { Between } 2 \text { and } 24 \mathrm{hrs} \\
\text { After } 24 \mathrm{hr}\end{array}$ & 3 & 1.4 \\
\hline \multirow[t]{2}{*}{ Mothers colostrum feed } & Yes & 224 & 93.5 \\
\hline & No & 15 & 6.5 \\
\hline Giving anything within 3days & Yes & 24 & 10.1 \\
\hline Other than breast milk feeding & No & 215 & 89.9 \\
\hline \multirow[t]{3}{*}{ what was given } & Cow and breast milk & 7 & 2.9 \\
\hline & Breast milk only & 2 & 0.8 \\
\hline & Formula & 15 & 6.3 \\
\hline \multirow[t]{3}{*}{ Reasons for pre-lacteal feeding } & Milk did not come in ye & 9 & 6.4 \\
\hline & I was ill & 12 & \\
\hline & Baby was ill & 3 & 1.25 \\
\hline \multirow[t]{2}{*}{ Dose Still breastfeeding } & Yes & 200 & 83.7 \\
\hline & No & 39 & 16.3 \\
\hline \multirow[t]{5}{*}{ Frequency of breastfeeding } & Less than 8 times & 38 & 16.2 \\
\hline & $8-10$ times & 102 & 42.5 \\
\hline & Frequent and on- & 81 & 33.8 \\
\hline & demand & 18 & 7.5 \\
\hline & Greater than 10 times & & \\
\hline \multirow[t]{4}{*}{ Exclusive breastfeeding practice to your child } & $0-6$ months & 162 & 67.5 \\
\hline & 6-12 months & 50 & 20.8 \\
\hline & Above 12 months & 3 & 1.3 \\
\hline & Not yet started & 24 & 10.4 \\
\hline \multirow[t]{5}{*}{ Type of complimentary food started } & Fluid & 47 & 19.6 \\
\hline & Simi fluid & 91 & 37.9 \\
\hline & family food & 52 & 21.7 \\
\hline & Not yet started & 6 & 2.5 \\
\hline & Other & 44 & 18.3 \\
\hline \multirow[t]{6}{*}{ Starting age of complementary feeding } & At 6 months & 128 & 53.6 \\
\hline & After 5 months & 7 & 2.9 \\
\hline & 2-4 months & 27 & 11.3 \\
\hline & After 6 month & 68 & 28.5 \\
\hline & Underage & 8 & 3.3 \\
\hline & Not yet started & 1 & .4 \\
\hline \multirow[t]{6}{*}{ Who supports you during breastfeeding? } & Husband & 88 & 36.7 \\
\hline & Another family & 78 & 32.7 \\
\hline & member & 73 & 30.6 \\
\hline & No one & & \\
\hline & Good practice & 206 & 86.2 \\
\hline & Poor practice & 33 & 13.8 \\
\hline
\end{tabular}


Table 7: Factors associated attitude of HIV positive mothers on EBF in a public health facility in the central zone, Tigray, Ethiopia 2019.

\begin{tabular}{|c|c|c|c|c|c|}
\hline bles & Kn & wledge & & COR $(95 \% \mathrm{CI})$ & AOR(95 \%CI) \\
\hline & & Good & Poor & & \\
\hline lence & Rural & $27(12.9)$ & $7(25)$ & 1 & 1 \\
\hline & Urban & $183(87.1$ & $21(75)$ & $\begin{array}{l}2.259(.877 \\
-5.819)\end{array}$ & $2.96(.948-9.29)$ \\
\hline rnal & illiterate & $80(38.1)$ & $15(51.7)$ & 1 & 1 \\
\hline ıtional level & literate & $130(61.9)$ & $14(48.7$ & $\begin{array}{l}1.74(0.736- \\
3.586)\end{array}$ & $1.37(.564$ \\
\hline hly income & $>=1500$ birr & $126(60$ & 19(67.9) & 1 & \\
\hline & $1000-$ & $51(24.3)$ & $3(10.7)$ & 2.56(.72- & 5.57(1.176- \\
\hline & 1500birr & $33(15.7)$ & $6(21.4)$ & 9.041) & $26.38) *$ \\
\hline & $<1000$ bir & & & $\begin{array}{l}0.829(.307- \\
2.242\end{array}$ & $1.48(.43$ \\
\hline t first birth & $18-24$ & $172(81.9)$ & $18(64.3)$ & 1 & \\
\hline & 24 and & $38(18.1)$ & $10(35.7))$ & $.398(.170-$ & .339 \\
\hline rrs of postnatal & 1 visit & $180(85.2)$ & $25(89.3)$ & 1 & \\
\hline & $2-3$ visi & $26(12.4)$ & $1(3.6)$ & $3.63(.472-27$ & $5.2($. \\
\hline & Above 3 visit & $5(2.4)$ & $2(7.1)$ & $.349(.064-1.89)$ & .312 \\
\hline s of health & Health post & $14(6.7)$ & $5(17.9)$ & 1 & \\
\hline facility & Health & $93(44.3)$ & $10(35.7)$ & $3.32(.98-$ & $2.77(.712-10.7)$ \\
\hline able & $\begin{array}{l}\text { center } \\
\text { Hospital }\end{array}$ & 104(49 & $13(46.4)$ & $\begin{array}{l}11.15) \\
2.8(0.87-9.14\end{array}$ & $1.84(.485-6.9)$ \\
\hline
\end{tabular}

Note: *-significant results, 1-reference category ${ }^{* *} p$-value $<0.001,{ }^{*} p$-value $\leq 0.05$

Table 8: Factors associated practice of HIV positive mothers on EBF in a public health facility in the central zone, Tigray, Ethiopia 2019. 


\begin{tabular}{|c|c|c|c|c|c|}
\hline \multirow[t]{2}{*}{ Variables } & \multicolumn{3}{|c|}{ practice } & \multirow{2}{*}{$\begin{array}{l}\text { COR } \\
(95 \% \mathrm{CI})\end{array}$} & \multirow{2}{*}{$\begin{array}{l}\text { AOR(95 } \\
\% \text { CI })\end{array}$} \\
\hline & & $\begin{array}{l}\text { Poor } \\
\text { practice } \\
\%\end{array}$ & $\begin{array}{l}\text { Good } \\
\text { practise } \\
\%\end{array}$ & & \\
\hline Maternal & Illiterate & 38(39.6) & $38(26.4)$ & 1 & 1 \\
\hline $\begin{array}{l}\text { educational } \\
\text { statues }\end{array}$ & Literate & $58(60.4)$ & $105(73.6)$ & $\begin{array}{l}1.828(1.052- \\
3.174)\end{array}$ & $\begin{array}{l}1.351(.626- \\
2.916)\end{array}$ \\
\hline Income & $\begin{array}{l}<1000 \\
1000-1500 \\
>1500\end{array}$ & $\begin{array}{l}22(22.9) \\
23(24) \\
51(53.1)\end{array}$ & $\begin{array}{l}17(11.8) \\
31(21.5) \\
96(66.7\end{array}$ & $\begin{array}{l}1.744(.759- \\
4.006) \\
2.436(1.88- \\
4.996) \\
1\end{array}$ & $\begin{array}{l}.625(.235- \\
1.66) \\
1.322(.530- \\
3.294) \\
1\end{array}$ \\
\hline Types of health & Health post & $5(5.2)$ & $14(9.7)$ & 1 & 1 \\
\hline care facility & $\begin{array}{l}\text { Health center } \\
\text { Hospital }\end{array}$ & $\begin{array}{l}44(45.8) \\
47(49\end{array}$ & $\begin{array}{l}61(42.4) \\
69(47.8\end{array}$ & $\begin{array}{l}.495(0.166- \\
1.476) \\
.524(0.177- \\
1.554)\end{array}$ & $\begin{array}{l}.499(.141- \\
1.766) \\
.427(.12- \\
1.527)\end{array}$ \\
\hline No of gravidity & $\begin{array}{l}\text { Primi gravid } \\
\text { Multi gravid } \\
\text { Grandmultigravia }\end{array}$ & $\begin{array}{l}71(74) \\
20(20.8) \\
5(5.2)\end{array}$ & $\begin{array}{l}117(81.9) \\
22(15.3) \\
4(2.8)\end{array}$ & $\begin{array}{l}1 \\
. .0667(.290- \\
1.056) \\
.4854(0.161- \\
2.068)\end{array}$ & $\begin{array}{l}1 \\
.619(.289- \\
1.328) \\
1.055(.246- \\
4.519)\end{array}$ \\
\hline No of ANC visit & $\begin{array}{l}1-2 \\
3-4 \\
>4\end{array}$ & $\begin{array}{l}71(74) \\
20(20.8) \\
5(5.2)\end{array}$ & $\begin{array}{l}21(14.6) \\
111(77.1) \\
12(8.3)\end{array}$ & $\begin{array}{l}1 \\
2.176(.971- \\
4.8981) \\
2.543(.895- \\
7.239)\end{array}$ & $\begin{array}{l}1 \\
2.981(1.113- \\
7.983)^{*} \\
3.726(1.055- \\
13.154)\end{array}$ \\
\hline
\end{tabular}

Note: *-significant results, 1 -reference category ${ }^{* *} p$-value $<0.001,{ }^{*} p$-value $\leq 0.05$ 